\title{
PEMANFAATAN LIMBAH SERPIHAN TANDUK KERBAU MENJADI PRODUK PEGANGAN GOLOK DENGAN TEKNOLOGI TEPAT GUNA
}

\author{
R. Ismet Rohimat, Hennie Husniah,Rosad Ma'ali Elhadi \\ Jurusan Teknik Industri, Fakultas Teknik - UNLA \\ Jalan Karapitan No.116 Bandung 40261 \\ E-mail : ismet.rohimat@gmail.com
}

\begin{abstract}
Recently, the usage of animal horn in Indonesia as a hand craft has a great attention especially for a dirk. handycrafter. The shortage of such horn as raw material becomes a problem for the horn and dirk handycrafter. Implication of that is a gap between demand and supply in the market. To over come this condition, we design two machines-milling machine and pressing machinethat changing the scrap of horn processing into a useable raw material. The idea is converted the waste by using milling and pressing process. The result not only profitable for the horn bandy-crafter, it also gives benefition solution for the green production process by making a better environment
\end{abstract}

Keywords : waste, buffalo horns, machete handles

\section{PENDAHULUAN}

Limbah adalah buangan yang dihasilkan dari suatu proses produksi baik industri maupun domestik (rumah tangga). Di mana masyarakat bermukim, di sanalah berbagai jenis limbah akan dihasilkan, jika tidak dikelola dengan baik akan berdampak negatif. Beberapa pengertian tentang limbah:

1. Berdasarkan keputusan Menperindag RI No. 231/MPP/Kep/7/1997 Pasal I tentang prosedur impor limbah, menyatakan bahwa Limbah adalah bahan/barang sisa atau bekas dari suatu kegiatan atau proses produksi yang fungsinya sudah berubah dari aslinya.

2. Berdasarkan Peraturan Pemerintah No. 18/1999 Jo.PP 85/1999 Limbah didefinisikan sebagai sisa atau buangan dari suatu usaha dan/atau kegiatan manusia.

Limbah berdasarkan sumbernya [1] limbah domestik atau rumah tangga, limbah industri, limbah pertanian, limbah pertambangan, limbah pariwisata, limbah medis. Sedangkan limbah erdasarkan sifat kimianya [2] yaitu organik dan anorganik

Dampak yang ditimbulkan dari limbah antara lain [3] : gangguan terhadap kesehatan, gangguan terhadap kehidupan biotik, gangguan terhadap keindahan dan gangguan terhadap benda.

Tanduk di Indonesia sudah umum digunakan dalam berbagai hasil kerajinan tanduk yang banyak diminati seperti sendok, garpu, tempat perhiasan, sisir, tongkat, penggaruk punggung, tusuk konde 
dan pengrajin golok yang memanfaatkan tantuk sebagai pegangannya, hingga kini terus mengupayakan agar pasokan permintaan tanduk dapat terpenuhi.

Seperti halnya kemasan yang lain, tanduk sesudah dimanfaatkan sebagai pegangan golok, serpihannya akan dibuang sebagai limbah. Serpihan tanduk merupakan material yang sukar terdegradasi di alam, sehingga akan terjadi akumulasi limbah tanduk di lingkungan. Laju akumulasi yang tinggi akan menyebabkan beban pencemaran semakin berat, sehingga diperlukan jalan keluar pemecahannya.

Seiring dengan pertambahan jumlah penduduk, masalah limbah padat serpihan tanduk hasil proses produksi pegangan golok semakin lama semakin menjadi masalah yang cukup serius terutama di daerah sentra kerajinan golok. Struktur tanah akan berubah akibat penguburan serpihan tanduk, oleh karena itu diperlukan metode alternatif pengolahan limbah serpihan tanduk sebelum dibuang/dikubur. Serpihan tanduk selain digunakan sebagai karya seni, dapat juga dimanfaatkan kembali menjadi produk pegangan golok dan pisau.

Oleh karena itu perlu membuat metode proses produksi serpihan tanduk agar dapat dimanfaatkan kembali menjadi produk pegangan golok dan pisau sehingga dapat mengurangi pencemaran lingkungan akibat akumulasi limbah serpihan tanduk (benefit) dan dapat memberikan nilai tambah (profit), di Kecamatan Manonjaya Kabupaten Tasikmalaya khususnya Desa Cilangkap Dusun Galonggong merupakan salah satu kawasan yang memproduksi golok dengan ciri khas pegangan atau gagang glok yang terbuat dari tanduk kerbau. Di beberapa daerah di Jawa Barat biasanya pegangan golok terbuat dari kayu atau plastik, namun ciri khas dari pegangan golok dan pisau galonggong semua terbuat dari tanduk kerbau. Sampai saat ini penelitian pegangan golok yang terbuat dari limbah tanduk ini belum banyak yang mendalaminya, meskipun teknologi yang digunakannya sangat sederhana.

Pada penelitain ini, salah satu jenis pengolahan limbah serpihan tanduk adalah merancang instalasi pengolahan limbah serpihan tanduk dengan sistem pemanfaatan kembali serpihan tanduk menjadi produk pegangan golok dan pisau dengan menggunakan teknologi tepat guna sehingga memberikan manfaat bagi masyarakat pedesaan.

\section{METODE}

\subsection{Metode Pengumpulan Data}

Pengumpulan data dilakukan sebagai langkah awal dalam sebuah penelitian dan bahan yang mendukung dalam penelitian ini.

Berdasarkan survey dan data yang dilakukan di kecamatan Manonjaya Kabupaten Tasikmalaya, terdapat sentra usaha masyarakat yang bergerak di bidang pembuatan pegangan golok dari tanduk saat ini tidak kurang dari 350 orang dengan rata-rata produksi 3-4 unit per hari. Untuk limbahnya sendiri tersebut menghasilkan rata-rata $500 \mathrm{~kg} /$ hari limbah serpihan tanduk, sehingga bahan baku selalu tersedia setiap harinya;

a. Bahan penunjang/pendukung yang diperlukan cukup tersedia di pasaran lokal;

b. Pangsa pasar produk pegangan golok masih terbuka luas, karena pengrajin golok saat ini selalu kekurangan tanduk.

\subsection{Metode Pengolahan Data}

50 | Pemanfaatan Limbah Serpiban Tanduk Kerbau Menjadi Produk Pegangan Golok Dengan Teknologi Tepat Guna 
Seiring dengan pertambahan jumlah penduduk, masalah limbah padat serpihan tanduk hasil proses produksi pegangan golok semakin lama semakin menjadi masalah yang cukup serius terutama di daerah sentra kerajinan golok. Struktur tanah akan berubah akibat penguburan serpihan tanduk, oleh karena itu diperlukan metode alternatif pengolahan limbah serpihan tanduk sebelum dibuang/dikubur.

Permasalahan pencemaran limbah mangancam ekosistem. Selain berdampak negatif bagi manusia, limbah juga berdampak negatif bagi lingkungan. Dampak negatif yang paling terlihat jelas adalah rusaknya lingkungan sehingga menurunkan nilai estetika lingkungan atau dengan kata lain lingkungan menjadi tidak enak dipandang.

Penggunaan secara maksimal bahan mentah yang dipakai dan sumber-sumber terbarui (renewable) menghasilkan keberlanjutan (suistanable) penggunaan sumber daya alam dan penghematan (efisiensi) terutama bagi limbah yang masih mengandung nilai ekonomis.

Beberapa faktor yang memengaruhi kualitas limbah adalah volume limbah, kandungan bahan pencemar, dan frekuensi pembuangan limbah. Untuk mengatasi limbah ini diperlukan pengolahan dan penanganan limbah. Pada dasarnya pengolahan limbah ini dapat dibedakan menjadi:

1. Pengolahan menurut tingkatan perlakuan

2. Pengolahan menurut karakteristik limbah

Beberapa jenis limbah dapat didaur ulang sehingga menghasilkan barang lain yang dapat digunakan. Sebagian besar limbah yang dapat didaur ulang adalah limbah anorganik seperti botol plastik, kaleng bekas, kain perca, pecahan kaca/keramik dan lain sebagainya. Daur ulang limbah jika dilakukan oleh orang-orang yang mempunyai kreativitas maka akan menghasilkan barang-barang baru yang berguna serta memiliki nilai estetika tinggi seperti daur ulang limbah menjadi kerajinan tangan.

\subsection{Limbah Tanduk Kerbau}

Tanduk adalah sebuah tonjolan berupa cula berjumlah dua yang tumbuh di kepala ternak/hewan. Pertumbuhan tanduk pada ternak/hewan mirip dengan pertumbuhan kukunya,namun konsistensinya lebih tebal, lebih keras, dan lebih besar. Ketika tumbuh, tanduk tertutup oleh lapisan kulit tipis seperti beludru, namun saat tanduk tumbuh dengan bentuk yang sempurna, maka beberapa sel dari jaringan tersebut menjadi rusak sehingga tidak dapat lagi memberi makan bagi sel dari jaringan yang menyusun lapisan kulit tersebut.

Tanduk kerbau sebagai salah satu limbah dari RPH dimana tanduk ini bagi kebanyakan RPH langsung di buang padahal dalam tanduk ini masih terdapat nilai ekonomi nya berikut pemanfaatan tanduk kerbau yang akan meningkatkan nilai ekonominya :

1. Pegangan golok atau pisau biasa digunakan oleh pandai besi

2. Bahan kerajinan gelang

3. Bahan kerajinan cincin dan kalung

4. Bahan kerajinan padudan

5. Sebagian kepercayaan orang dimana tanduk sapi bisa digunakan untuk pengobatan

6. Sarana pengobatan bekam

Banyak yang dilakukan orang untuk memanfaatkan limbah tanduk terutama untuk hiasan saja, sehingga nilai ekonomis nya masih kecil, dan penggunaan teknologinya juga masih sangat sederhana.

Serpihan tanduk digiling sampai berubah menjadi serbuk tanduk, dianalisis unsur-unsur yang terdapat dalam serbuk, serbuk tersebut dipres dengan terlebih dahulu harus dibuat formulasi yang lebih baik 
antara diameter serbuk, banyaknya zat perekat dan tekanan, untuk menghasilkan produk pegangan golok kembali yang berkualitas. Hasil akhirnya adalah limbah serpihan tanduk yang bermanfaat, dengan tidak menghasilkan limbah tetapi menghasilkan nilai tambah dan bermanfaat bagi warga disekitar sentra industri golok.

Pemanfaatan limbah tanduk yang banyak terdapat di Kabupaten Tasikmalaya merujuk pada komitmen Kabupaten Tasikmalaya dalam pengembangan kerajinan golok Galonggong yang menggunakan tanduk untuk pegangan golok.

Pengrajin pegangan golok sampai saat ini selalu kekurangan tanduk dengan perkataan lain permintaan produk golok tidak dapat terpenuhi, solusinya adalah pemanfaatkan kembali limbah serpihan tanduk untuk diproses menjadi pegangan golok. Tahapan penelitiannya dapat lihat pada gambar 1.

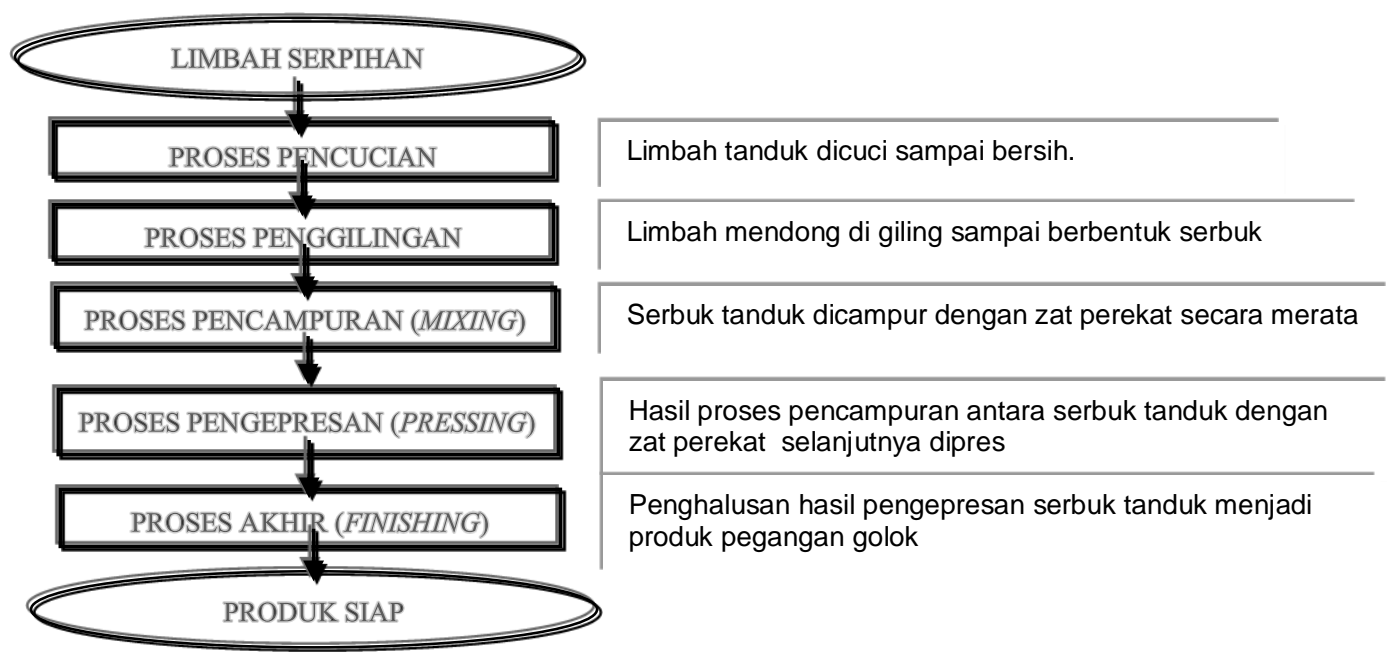

Gambar 1: Langkah-langkah Proses Pemanfaatan Limbah Tanduk Menjadi Produk Pegangan Golok

\section{HASIL DAN PEMBAHASAN}

Sentra industri golok Galonggong di Kecamatan Manonjaya Kabupaten Tasikmalaya setiap hari memproduksi golok dan pisau siap jual, sehingga serpihan tanduk terus bertambah secara kumulatif, limbah serpihan tanduk tersebut dapat digunakan sebagai bahan-baku produk pegangan golok. Pengrajin golok Galonggong selalu kekurangan tanduk, yang berakibat permintaan pasar tidak dapat terpenuhi, hal tersebut merupakan peluang pasar yang masih terbuka lebar. Tanduk sebagai bahan baku produk pegangan golok dan pisau dapat dilihat pada gambar 2 .

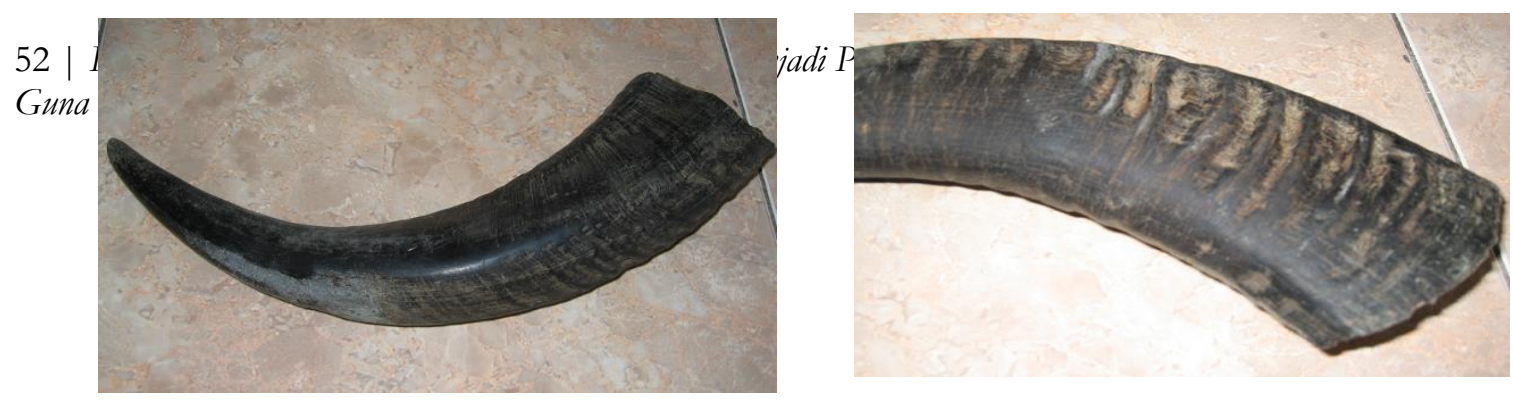


Gambar 2: Tanduk Sebagai Bahan Baku Produk Pegangan Golok dan pisau

1. Bahan Baku dan Bahan Penunjang

Kapasitas produksi pembuatan pegangan golok dengan pemanfaatan limbah serpihan tanduk (lihat gambar 3) salah satunya dapat ditentukan dari banyaknya limbah serpihan tanduk di sentra pengrajin golok Galonggong Kecamatan Manonjaya Kabupaten Tasikmalaya. Berdasarkan survey dan data yang dilakukan di kecamatan Manonjaya Kabupaten Tasikmalaya, terdapat sentra usaha masyarakat yang bergerak di bidang pembuatan pegangan golok dari tanduk saat ini tidak kurang dari 350 orang dengan rata-rata produksi 3-4 unit per hari. Untuk limbahnya sendiri tersebut menghasilkan rata-rata $500 \mathrm{~kg} /$ hari limbah serpihan tanduk, sehingga bahan baku selalu tersedia setiap harinya;

c. Bahan penunjang/pendukung yang diperlukan cukup tersedia di pasaran lokal;

d. Pangsa pasar produk pegangan golok masih terbuka luas, karena pengrajin golok saat ini selalu kekurangan tanduk.

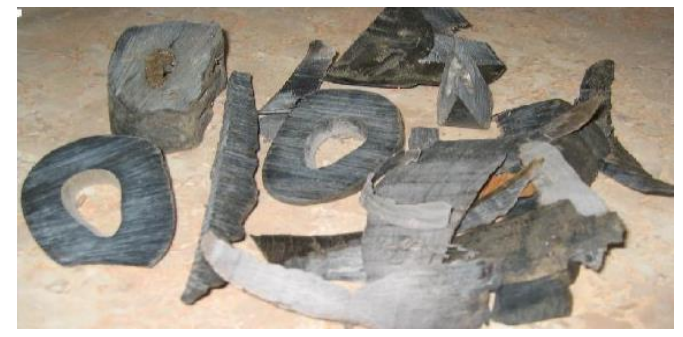

Gambar 3: Limbah Serpihan Tanduk

2. Rancangan dan Pembuatan Alat

Rancangan dan pembuatan alat memperhatikan hal-hal sebagai berikut :

a. Menggunakan bahan-bahan yang banyak di pasaran;

b. Sederhana dan mudah dioperasikan;

c. Biaya cukup terjangkau;

d. Mudah perbaikan dan perawatan;

e. Menggunakan teknologi tepat guna.

Pada tahapan ini alat di rancang dan digambar berdasarkan standar dan gambar teknik, sehingga akan diketahui ukuran dan jenis bahan-bahan yang akan digunakan. Sistem pengolahan serpihan tanduk menjadi produk pegangan golok dan pisau memerlukan peralatan yang dirancang dan dibuat mulai dari rancangan alat penghancur serpihan tanduk sampai dengan produk jadi, dapat dilihat dalam gambar 4 dan 5 [4] 


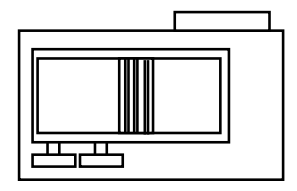

Pandangan Atas

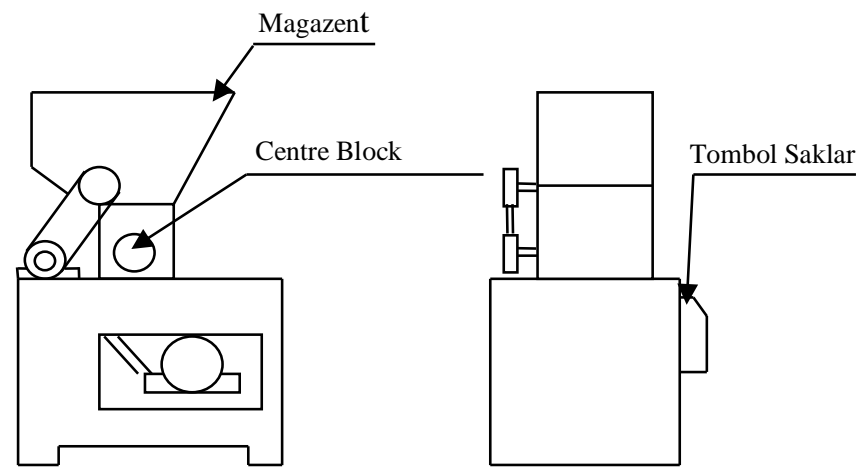

Pandangan Depan

Pandangan Samping Kanan

Gambar 4 : Rancangan Mesin Giling Serpihan Tanduk

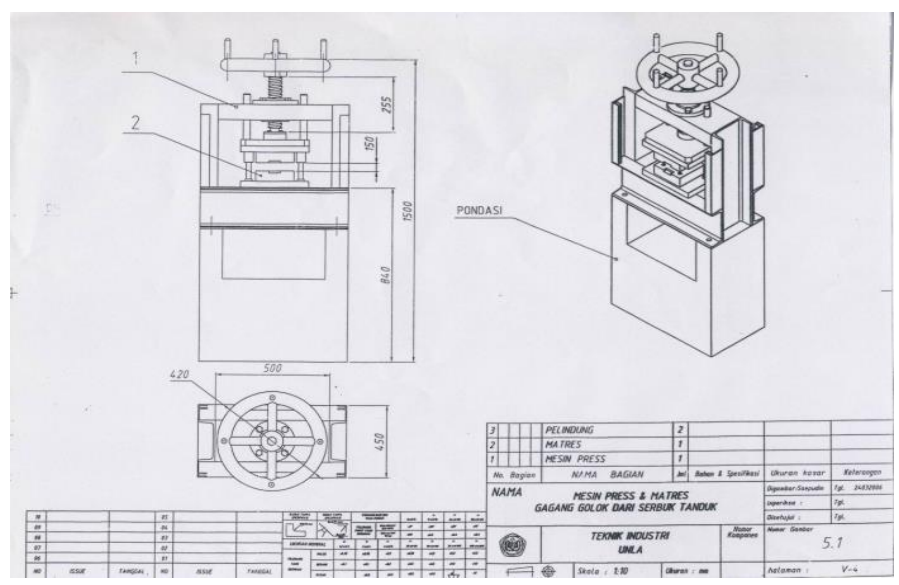

Gambar 5: Rancangan Mesin Pres Serbuk Tanduk

3. Potensi Dampak Inovasi

Upaya pemanfaatan kembali limbah serpihan tanduk sebagai bahan baku proses produksi pegangan golok, diharapkan dapat mengurangi jumlah limbah serpihan tanduk di sentra kerajinan tanduk serta sekaligus dapat membuka lapangan kerja baru yaitu bidang produksi pegangan golok dan produk souvenir lainnya.

Proses pembuatan produk pegangan golok dengan memanfaatkan limbah serpihan tanduk mempunyai prinsip dapat mengatasi masalah limbah serpihan tanduk yang ramah lingkungan (benefit), mendapat nilai tambah (profit) dan menggunakan teknologi tepat guna, merupakan ciri khas 54 | Pemanfaatan Limbah Serpihan Tanduk Kerbau Menjadi Produk Pegangan Golok Dengan Teknologi Tepat Guna 
rancangan proses pembuatan produk yang berdaya guna dan berhasil guna dengan memanfaatkan limbah serpihan tanduk, sehingga dalam sosialisasi pemanfaatan hasil inovasi tersebut dapat lebih efektif dan efisien. Hal tersebut dilakukan karena dalam proses produksi, biayanya relatif murah dan memberi keuntungan langsung maupun tidak langsung bagi pengrajin tanduk dan masyarakat sekitarnya. Hasil akhir produk pegangan golok dan pisau dapat dilihat pada gambar 6
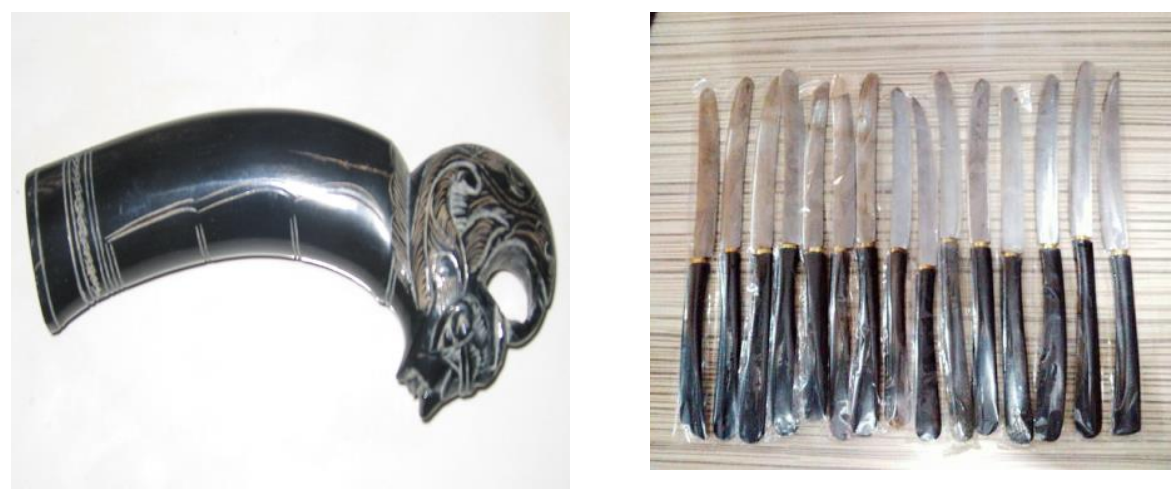

Gambar 6: Gambar Pegangan Golok

\section{KESIMPULAN}

1. Berkurangnya limbah serpihan tanduk di sentra industri/kerajinan tanduk;

2. Tersedianya peralatan pembuatan produk pegangan golok dengan memanfaatkan limbah serpihan tanduk sebagai bahan bakunya;

3. Tersedianya produk pegangan golok yang siap dipasarkan;

4. Membuka lapangan kerja baru sekaligus mengurangi tingkat pengangguran.

\section{DAFTAR PUSTAKA}

[1] Zulkifli, Arif. 2014. Dasar-Dasar Ilmu Lingkungan. Jakarta: Salemba Teknika.

[2] Wardhana, Arya. 2004. Dampak Pencemaran Lingkungan, Cetakan Keempat. Yogyakarta: Andi.

[3] Sugiharto. 1987. Dasar-dasar pengelolaan air limbah. Jakarta: Universitas Indonesia.

[4] Amstead B.H.; 1992; Teknologi Mekanik; Jilid 1 dan 2; Edisi Ketujuh; Erlangga; Jakarta

[5] Kristianto. 2004. Ekologi Industri. Yogyakarta: Andi. 